Indexed by

\title{
Scopus
}

\section{SHEAR STRENGTHENING AND REHABILITATING OF REINFORCED CONCRETE T-BEAMS USING EXTERNALLY CARBON FIBER REINFORCED POLYMER SHEETS}

Crossref

\section{Mervat Beramly}

School of Engineering, Department of Civil Engineering, The University of Jordan, Amman, Jordan

\section{Mutasim Abdel-Jaber}

Faculty of Engineering,

Department of Civil Engineering, Al-Ahliyya Amman University, Jordan

\author{
Hasan Katkhuda \\ Faculty of Engineering, Department \\ of Civil Engineering, The Hashemite \\ University, Zarqa, Jordan, \\ P.O.Box 330127, 13133 Zarqa, \\ Jordan
}

KOBSON

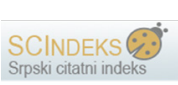

Nasim Shatarat

School of Engineering, Department of Civil Engineering, The University of Jordan, Amman, Jordan

\author{
Malak Al-diseet \\ School of \\ Engineering, Department \\ of Civil Engineering, The \\ University of Jordan, \\ Amman, Jordan
}

Key words: T-beams, reinforced concrete, shear behavior, CFRP, experimental study, theoretical study

doi: $10.5937 /$ jaes0-34390

Cite article:

Beramly M., Abdel-Jaber M., Katkhuda H., Shatarat N., Al-diseet M. (2022) SHEAR STRENGTHENING AND REHABILITATING OF REINFORCED CONCRETE T-BEAMS USING EXTERNALLY CARBON FIBER REINFORCED POLYMER SHEETS, Journal of Applied Engineering Science, 20(2), 498 - 510, DOI:10.5937/ jaes0-34390

Online aceess of full paper is available at: www.engineeringscience.rs/browse-issues 


\title{
SHEAR STRENGTHENING AND REHABILITATING OF REINFORCED CONCRETE T-BEAMS USING EXTERNALLY CARBON FIBER REINFORCED POLYMER SHEETS
}

\author{
Mervat Beramly ${ }^{1}$, Mutasim Abdel-Jaber ${ }^{2}$, Hasan Katkhuda ${ }^{3, *}$, Nasim Shatarat', Malak Al-diseet ${ }^{1}$ \\ ${ }^{1}$ School of Engineering, Department of Civil Engineering, The University of Jordan, Amman, Jordan \\ ${ }^{2}$ Faculty of Engineering, Department of Civil Engineering, Al-Ahliyya Amman University, Jordan. On \\ Sabbatical leave from School of Engineering, Department of Civil Engineering, The University of Jordan, \\ Amman, Jordan \\ ${ }^{3}$ Faculty of Engineering, Department of Civil Engineering, The Hashemite University, Zarqa, Jordan, \\ P.O.Box 330127, 13133 Zarqa, Jordan \\ ${ }^{4}$ School of Engineering, Department of Civil Engineering, The University of Jordan, Amman, Jordan
}

The shear behavior of reinforced concrete (RC) T-beams using externally bonded carbon fiber-reinforced polymers (CFRPs) composites is investigated experimentally and theoretically in this research. Nine RC T-beams were cast and tested under monotonic one-point loading. The variables used in this study are: the situation of specimens (strengthened or rehabilitated); type of CFRPs material (laminate or sheet); and the CFRPs configuration (inclined or horizontal). The experimental results were compared to theoretical results from nonlinear finite element (FE) models for T-beams using ABAQUS software. The experimental results showed that using different CFRPs materials in various configurations effectively improved shear capacity for strengthening and rehabilitating RC T-beams. Compared to the control beam, the three schemes used to strengthen the shear of RC T-beams were successful in increasing the maximum load capacity by a range of 13.6 to $36.4 \%$, and by 4.6 to $27.3 \%$ for rehabilitate T-beams. The included horizontal strips of CFRPs laminates achieved the highest increase in the shear capacity for strengthened T-beams. While, for the rehabilitated T-beams the results showed that the CFRP scheme that included full wrap of the web with CFRPs sheets was the best. A good agreement was found between the experimental and theoretical results. The differences in the ultimate loads and mid-span deflections were in the range of $0.33 \%$ to $26 \%$, and $0.32 \%$ to $6.6 \%$, respectively.

Key words: T-beams, reinforced concrete, shear behavior, CFRP, experimental study, theoretical study

\section{INTRODUCTION}

Large number of buildings designed using reinforced concrete $(\mathrm{RC})$ in recent decades is currently facing a number of problems, many of which have reached the end of their expected service life. Rehabilitation due to decay over time and the fact that the restoration of these structures is absent for historical, environmental, and economic reasons is one of the most relevant issues related to these structures. Many concrete structures have often been designed to carry loads that are smaller than the actual specifications or have modified their use, so there is a constant need to enhance their performance under current loads or to carry extra loads. Upgrading of concrete buildings can be accomplished using various methods and without impacting users or disabling normal operations. It is often difficult to provide easy, clear, efficient, and economical solutions. One of the most successful methods for restoration and reinforcing concrete structures is Fiber Reinforced Polymers (FRPs) composites. It is superior over the other techniques due to its lightweight, high strength, speed, and ease of in- stallation. Carbon fiber-reinforced polymers (CFRPs) offer another way of rapidly repairing or reinforcing $R C$ beams without interfering with the use of a framework or altering the geometry or weight of the repaired member [1]. Past studies of analytical solutions [2], experimental studies [3-15] or field applications have shown that the use of this technology has been extremely effective in practice $[19,20]$. Abdel-Jaber et al. [10] investigated 38 rectangular beams in order to provide specific guidance for strengthening $\mathrm{RC}$ rectangular beams with FRP materials. To reinforce the specimens in shear, different configurations of externally bonded CFRPs plates were chosen. The authors studied number of factors including the percentage of main (bottom) reinforcement, connection spacing in shear spans, and CFRPs strengthening configuration. The application of CFRPs strips to the shear spans of the beams increased the intensity by 19 to $56 \%$, according to their findings. Shear strengthening appeared to be more effective when two horizontal CFRPs strips were applied over the shear span and 
tension region. Feng et al. [11] studied the shear capability of eighteen pre-cracked rectangular $\mathrm{RC}$ beams shear-strengthened with U-jacketing CFRPs strips. The ratio of pre-cracked load to the ultimate bearing capacity of the unreinforced beams were measured for different CFRPs strip spacing, shear span ratio, and pre-cracked degree. The results showed that three failure modes of CFRPs strips-strengthened RC beams were observed: interfacial adhesion failure, de-bonding failure, and fracture failure of CFRPs strips. Also, as the spacing between CFRPs strips was reduced, the degree of shear capability of the specimens improved gradually. With the decrease in shear span ratio, the specimen's shear ability gradually increased. However, as the shear span ratio increased, the effect of CFRPs strip spacing on specimen shear capability decreased. RC T-shaped or inverted L-shaped beams are commonly used in slabs. There are two types of T-beams, depending on whether the beam casting coincides with the slab: (1) monolithic where the slab and beam are cast together; and (2) isolated where the beam and slab are not cast at the same time. In order to achieve a flanged part, the monolithic beam is used, where the beam works integrally with a portion of the slab. This portion of the slab would also bend in the same direction during beam bending, implying a greater concrete area, i.e. an increase in the compression region, in the upper portion to retain the compression and increase the beam lateral stability. This makes this type of beam preferable and more economical compared to the isolated T-beam because of the chance of a decrease in the amount of concrete. Few studies have been done on the shear strengthening and rehabilitating with CFRP for RC T-beams [4-7,16-19]. Bae et al. [16] examined the action of large-scale concrete bridge girders reinforced in shear with externally bonded CFRPs sheets using eight full-scale RC T-beams. The authors studied the effect of using different transverse steel reinforcement and anchorage techniques. The findings showed that the mechanical anchorage system offered additional shear strength, ranging from $7 \%$ to $48 \%$ higher than beams without mechanical anchorage. Kim et al. [17] evaluated the shear efficiency of beams reinforced externally with CFRPs laminates and anchors using sixteen RC T-beams. The main variables in the testing program were: shear span to depth ratio, amount of transverse steel, the layout and amount of CFRPs laminates, bond between the CFRPs laminates and the beam surface, and inclination of CFRPs anchors. The highest CFRPs shear contribution was found in beams with a shear span-to-depth ratio of 3.0, and the anchorage method which consisted of anchors made of the same CFRPs as the laminates worked well. Soliman [18] studied experimentally the shear behavior of five RC T-beams. Different spacing of CFRPs strands sum per strip and spacing between strips were the main factors in the study. The results showed that the sheets applied on the sides only with width of $30 \mathrm{~mm}$ and spacing at $170 \mathrm{~mm}$ from center to center of the strips increased the overall shear ability of the specimens by $22 \%$ compared to the control beam, and made the beam more ductile. El-Saikaly et al. [19] investigated the improvements of shear strength by testing twelve RC T-beams. The main variables were CFRPs sheets, CFRPL-strips and CFRPs L-strips and anchored with CFRPs rope. The results showed that by using the new technique for anchoring the CFRPs strips, the U-wrap scheme could be converted to a full-wrap scheme and de-bonding failure could be avoided. Lately some research on Near Surface Mounted (NSM)-CFRP were conducted as a new approach to improve the flexural and shear strengths of beams [20-22]. In this paper, the shear improvements of RC T-beams are investigated by using CFRP sheets. Nine RC T-beams were cast and tested under monotonic one-point loading. The variables used in this study were: the situation of specimens (strengthened or rehabilitated); type of CFRPs material (laminate or sheet); and the CFRPs configuration (inclined or horizontal). The experimental results were compared with the theoretical results by modeling the T-beams using ABAQUS FE software.

\section{EXPERIMENTAL INVESTIGATION}

\section{Beams Groups}

To assess the shear behavior of strengthened and rehabilitated RC beams with CFRP materials, experimental tests were carried out on a set of nine simply supported RC T- beams. The beams are categorized into four groups: The first group consists of only one beam; CB1. This beam has longitudinal and transverse steel but without CFRPs material attached to it. The main purpose of this beam was to use it as a reference by comparing the ultimate strength, mode of failure and the cracks pattern of this beam with the remaining beams to identify the best CFRPs configuration. The second group was plain group. It had two identical RC T-beams: PB1 and PB2. Those beams have longitudinal steel, no transverse steel, and without CFRPs material attached to them. The main purpose of this group was to compare the theoretically concrete shear capacity (Vctheo) with the experimental (Vcexp) of the beams. The third group is for strengthening beams which were strengthened with CFRP materials and then subjected to one concentrated load up to failure. This group consists of three beams; SB1, SB2, and SB3. The beams have same longitudinal and transverse steel, but three different configurations of CFRPs materials were used: (1) Inclined laminates at angle 450 on the side faces only along the shear spans (SB1); (2) Horizontal laminates at angle 0o on the side faces only along the shear spans (SB2); and (3) One layer of completely wrapped sheet over the entire web (SB3). The fourth group is for rehabilitated beams which were pre-loaded up to $60 \%$ of the capacity of the control beam CB1 and then the CFRP materials were added on each beam and tested again. The beams have same longitudinal and transverse steel, but three different configurations of CFRPs materials were used: (1) Inclined lam- 
Table 1: Beam groups details

\begin{tabular}{|c|c|c|c|c|}
\hline Group Name & Specimen Designation & $\begin{array}{c}\text { Transvers Steel } \\
\text { Reinforcement }\end{array}$ & CFRP material & Strengthening scheme \\
\hline $\begin{array}{c}\text { First Group } \\
\text { Control }\end{array}$ & CB1 & $\Phi 8 @ 150$ & --- & -- \\
\hline $\begin{array}{c}\text { Second Group } \\
\text { Plain }\end{array}$ & $\begin{array}{c}\text { PB1 } \\
\text { PB2 }\end{array}$ & --- & --- & - \\
\hline \multirow{3}{*}{$\begin{array}{c}\text { Third Group } \\
\text { Strengthened }\end{array}$} & SB1 & $\Phi 8 @ 150$ & Laminates & 45o Inclined \\
\cline { 2 - 5 } & SB2 & $\Phi 8 @ 150$ & Laminates & Horizontal \\
\hline \multirow{3}{*}{$\begin{array}{c}\text { Fourth Group } \\
\text { Rehabilitated }\end{array}$} & SB3 & $\Phi 8 @ 150$ & Sheets & $\begin{array}{c}\text { One layer-Wrapped over entire } \\
\text { web }\end{array}$ \\
\cline { 2 - 5 } & RB1 & $\Phi 8 @ 150$ & Laminates & 45 Inclined \\
\cline { 2 - 5 } & RB3 & $\Phi 8 @ 150$ & Laminates & Horizontal \\
\hline
\end{tabular}

inates at angle $45^{\circ}$ on the side faces only along the shear spans (RB1); (2) Horizontal laminates at angle 0o on the side faces only along the shear spans (RB2); and (3) One layer of completely wrapped sheet over the entire web (RB3). Table 1 and Figure 1 show the beam groups details and CFRP configurations, respectively.

\section{Beams Geometry and Reinforcement Details}

All beams have same span length of $2000 \mathrm{~mm}$ length and same cross section. The beams flange widths and thicknesses were $500 \mathrm{~mm}$ and $50 \mathrm{~mm}$, respectively. The web was $150 \mathrm{~mm}$ wide and the overall depth of the beams was $400 \mathrm{~mm}$. The beams were designed to behave as T-beams, i.e. N.A falls within the web, and to fail in shear rather than flexure. The design was according

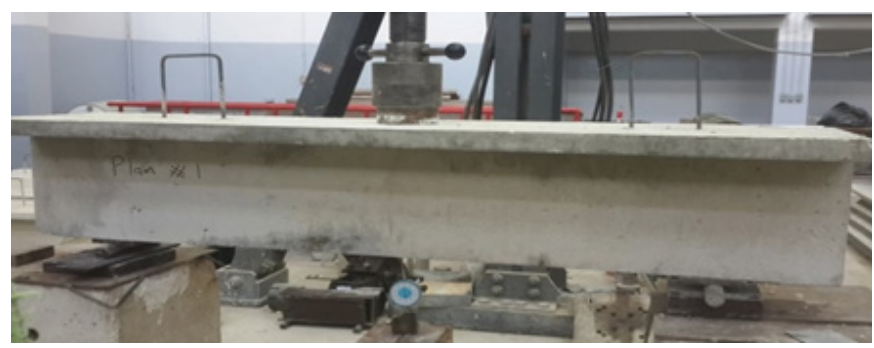

(a)

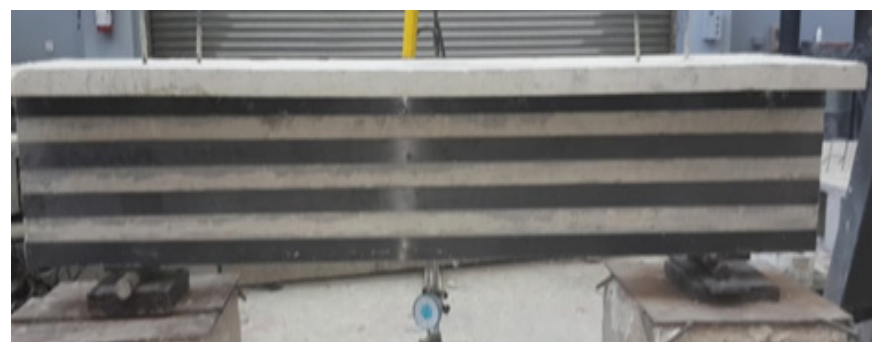

(c) to ACl318M-14 [23], [26] and [27] codes. The shear reinforcement was provided by vertical stirrups of $8 \mathrm{~mm}$ diameter steel bars spaced $150 \mathrm{~mm}$, center to center, over the span length for all the groups except for group two (the plain group). Group two had just three stirrups at the ends and the center to hold the longitudinal bars in position and to avoid any possibility of local failure at the supports. All beams had the same amount of flexural reinforcement; two $25 \mathrm{~mm}$ diameter bars arranged in the corner of the web and one $20 \mathrm{~mm}$ diameter bars placed in the middle of the web. Four of $8 \mathrm{~mm}$ diameter steel bars were used as top steel in the longitudinal direction in addition to a bar with a diameter of $8 \mathrm{~mm}$ every 150 $\mathrm{mm}$ in the transverse direction. The concrete cover was $25 \mathrm{~mm}$ in all directions. Figure 2 shows the beams geometry and reinforcement details.

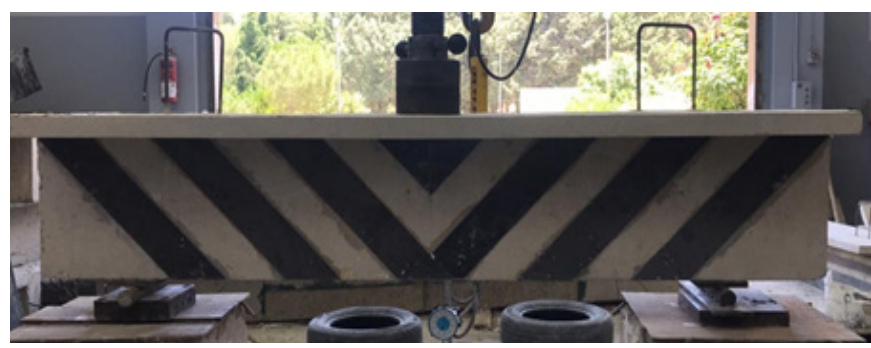

(b)

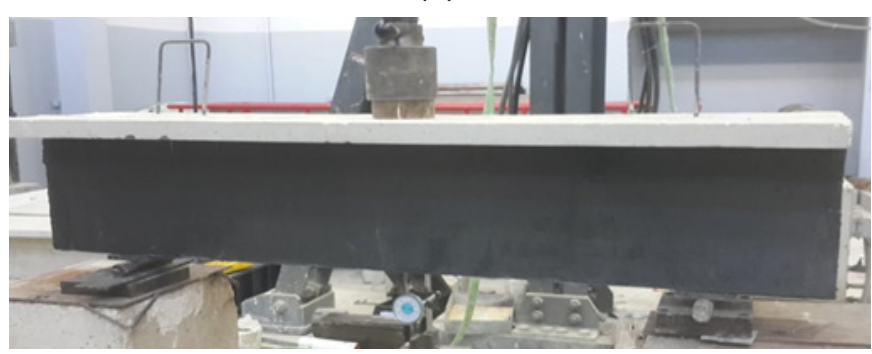

(d)

Figure 1: Beam CFRP configurations; (a) control- no CFRP; (b) 450 inclined; (c) horizontal; (d) one layer sheet wrapped over entire web. 

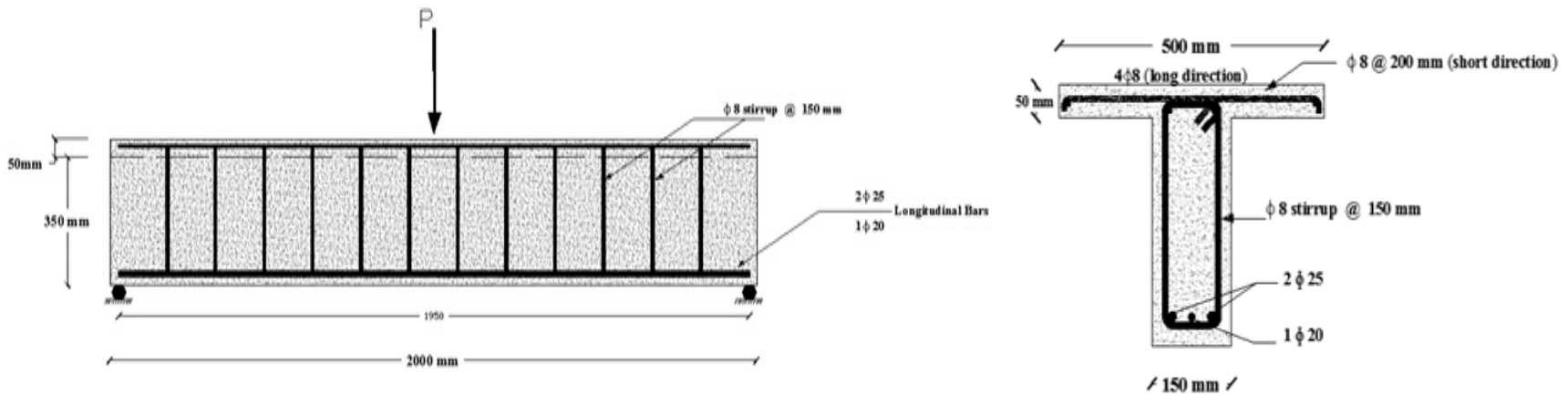

Figure 2: Beam geometry and reinforcement details

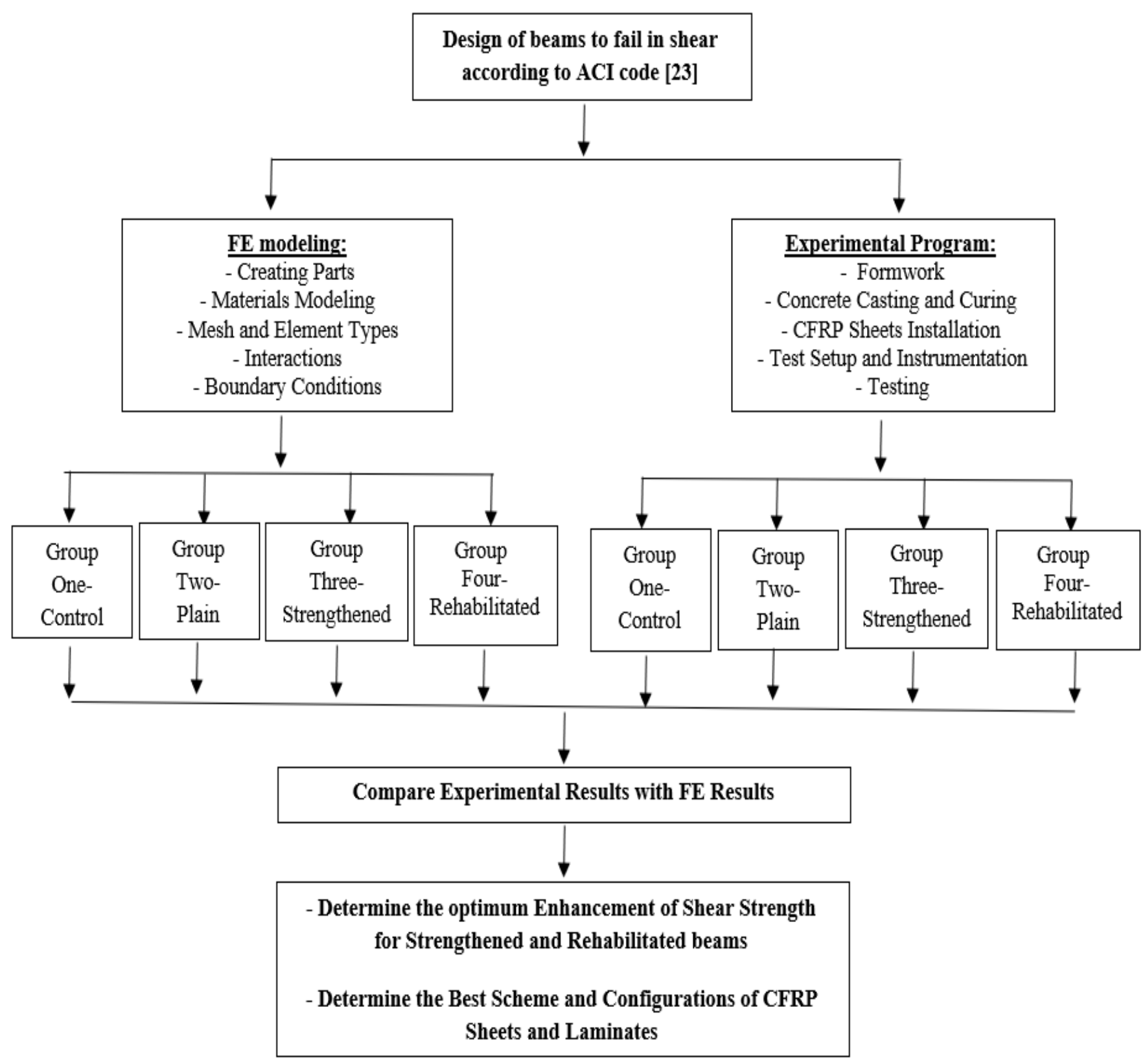

Figure 3: Flowchart of research methodology 


\section{Materials Properties}

\section{Concrete}

All beams were constructed using a ready-mixed normal weight concrete. The average cubic compressive strength after 28 days was $22.5 \mathrm{MPa}$. Cubes of $150 \times$ $150 \times 150 \mathrm{~mm}$ size were used to test the compressive strength of concrete at 28 days of curing. Three cubes were taken from the same concrete mixture and tested each time, and the average strength was calculated.

\section{Steel Reinforcement}

The type of reinforcement used in this research was high yield strength deformed bars with an average yield strength of $420 \mathrm{MPa}$ and ultimate strength of $680 \mathrm{MPa}$.

\section{CFRP Materials}

Two types of CFRPs were used to strengthen and rehabilitate the RC T-beams. First one was MBrace FIBER CF 230/4900 and the second one was MBrace LAMINATE 165/300. Both are carbon based. CFRP were high strength, light weight, which make them easy to carry, easy to cut, and to re-shape. Also they are having good fatigue properties. The properties of the CFRP materials according to the manufacturer's datasheets are shown in Table 2.

\section{Epoxy Resin}

Epoxy is considered an essential part in the experimental program because good epoxy prevents de-bonding between concrete surface and CFRP and as a result the de-bonding failure will be avoided. During strengthening procedure, two types of epoxy were used: MasterBrace AHD 2200 for laminate CFRP; and MasterBrace SAT 4500 for sheet CFRP. Both types composed of two parts: part A as resin; and part B as hardener. For MasterBrace AHD 2200, 3kg pack has been readily mixed by trowel till to achieve a smooth streak free consistency. While for MasterBrace SAT 4500, mechanical premix for part A prior to adding them to part $B$ for a minute. Then continue

Table 2: CFRP sheets properties

\begin{tabular}{|c|c|c|}
\hline & $\begin{array}{c}\text { MBrace } \\
\text { LAMINATE } \\
165 / 300\end{array}$ & $\begin{array}{c}\text { MBrace } \\
\text { FIBER CF } \\
230 / 4900\end{array}$ \\
\hline Material Type & Carbon & Carbon \\
\hline $\begin{array}{c}\text { Modules of Elasticity } \\
(\mathrm{GPa})\end{array}$ & $>210$ & 230 \\
\hline Tensile Strength (MPa) & $>2.8$ & 4.9 \\
\hline $\begin{array}{c}\text { Density of carbon fiber } \\
\left(\mathrm{g} / \mathrm{cm}^{3}\right)\end{array}$ & 1.6 & 1.76 \\
\hline Thickness $(\mathrm{mm})$ & 1.4 & 0.166 \\
\hline Width $(\mathrm{mm})$ & 100 & 500 \\
\hline
\end{tabular}

mechanical mixing after addition of part B for three minute or until the mix becomes homogeneous. Both types of epoxy should be used within half an hour after mixing because after this duration they will lose their strength.

\section{Construction of RC T-beams}

\section{Formwork}

The concrete was poured into high-quality steel molds with a T-shaped cross-section. A $6 \mathrm{~mm}$ thick steel plate was used to make durable and reusable molds with internal dimensions equal to that of RC T-beams. Each mold consists of four parts that assembled by bolts. The sides were supported by stiffeners distributed all over the length to avoid any local buckling. Figure 4 shows the formwork used for all specimens.

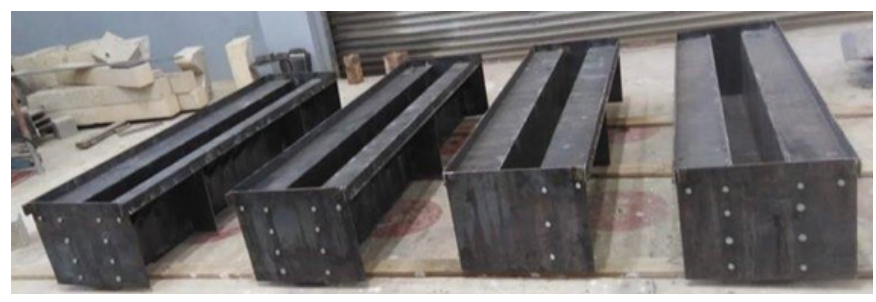

Figure 4: Formwork used for all specimens

\section{Concrete Casting and Curing}

The mold surfaces were lubricated to prevent sticking of concrete. Reinforcing steel bars were inserted inside the formwork. Concrete was gradually poured and vibrated by mechanical vibrator. Top surfaces were leveled and smoothed. After two days of casting, the molds were removed and then the beams were cured with wet burlap for 7 days, followed by curing in the air for 21 days.

\section{CFRP Sheets Installation:}

The CFRPs materials were installed after the beams were gained the required strength within 28 days. The surfaces of beams were cleaned from any dust and loose materials to insure good bond between RC T-beams and CFRPs. At the same time, CFRPs materials were cleaned from any unsuitable things like dust or oil stains and then cut to the required length. Epoxy was mixed according to the instructions which were obtained from the manufacturer. Thin layer of $3 \mathrm{~mm}$ of the epoxy was applied on beams, after that CFRPs laminate or sheet was placed on the painted epoxy according to the applicable scheme. Entrapped air bubbles were removed by knocking on the CFRPs using hammer and rolling the air-bubbles out using a roller. The beams were tested after 14 days of curing the epoxy in the air.

\section{Test Setup and Instrumentation:}

The nine RC T-beams were subjected to a monotonic loading which was represented by a single concentrated 
load at the mid-span. The application of the monotonic load was achieved by using a 700-kN MFL Prüf-systeme Universal Testing Machine, as the load was applied incrementally in $10 \mathrm{kN}$ steps up to failure. At the end of each step, the location of cracks and their propagation was clearly marked on the concrete surface, as well as the load capacity and the deflection at the mid-span of the beam were recorded. The deflection was measured using a dial gauge placed at the mid-span under the soffit of the beam, while the load was measured by using a load cell. All the beams were simply-supported. The three beams in group four (rehabilitated) were loaded up $60 \%$ of the CB capacity, and then rehabilitated with CFRP materials each in its configuration. Figure 5 shows a photo for test setup.

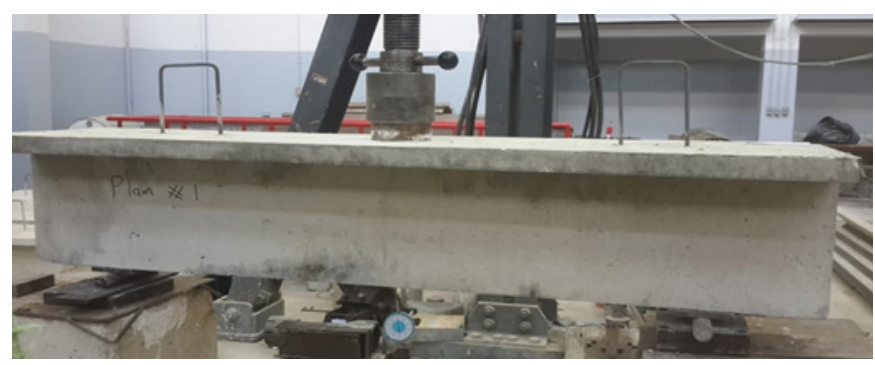

Figure 5: Test setup

\section{FINITE ELEMENT MODELING}

Based on the experimental program, the RC T-beams were modeled using ABAQUS FE software. Then the results of the FE modeling are compared with the experimental results.

\section{Modeling Procedure}

\section{Creating the Parts}

The beams were constructed from the parts of: concrete, stirrups, steel bars, and CFRP materials. The concrete was 3D solid shape, stirrups and steel bars were 3D wire shape, and CFRP materials were 3D shell shapes. A 100 $\times 150 \times 20 \mathrm{~mm}$ thickness steel plate was used to load the samples in the same conditions as the experimental test. The steel plate was 3D solid shape.

\section{Materials Modeling}

\section{Steel}

Elastic-perfectly plastic model was used in defining the stress-strain performance of the steel material. The modulus of elasticity and Poisson's ratio were $200000 \mathrm{MPa}$ and 0.3 , respectively. The yield stress was $420 \mathrm{MPa}$ with zero corresponding plastic strain.

\section{Concrete}

\section{Elastic Phase}

The modulus of elasticity of concrete was determined using the following equation:

$E c=w c^{1.5}(0.043) \sqrt{f^{\prime} c}$

Where wc is the weight of the concrete and f'c is the compressive strength.

\section{Plastic Phase}

The concrete damaged plasticity (CDP) model provided in the software was used. Tsai's constitutive model equations [24] were used to obtain mechanical plastic isotropic behavior using the compressive and tensile behavior. Tension and compression damage parameters (dc, dt) with values ranging from zero to one were used in the CDP model to describe the deterioration in concrete stiffness and strength due to tensile cracking and compressive crushing. The undamaged content is represented by zero, and the complete loss of strength is represented by one. The following equations were used to calculate the two harm variables in this analysis [25]:

$$
\begin{aligned}
& d_{c}=1-\frac{\sigma_{c}}{f^{\prime}{ }_{c o}} \\
& d_{t}=1-\frac{\sigma_{t}}{f^{\prime}{ }_{t o}}
\end{aligned}
$$

Where:

$\sigma_{c}$ : concrete compressive stress along the descending stress-strain curve.

$f^{\prime}{ }_{\text {co }}$ : concrete compressive stress at the peak point.

$\sigma_{t}$ : concrete tensile stress along the descending stressstrain curve.

$f_{\text {to }}^{\prime}$ : concrete tensile stress at the peak point.

\section{CFRP Sheet}

The behavior of CFRPs materials was modeled as absolute elastic up to failure. The cohesive properties were not specified because a perfect bond between the CFRPs material and the concrete surface was assumed using a tie element.

\section{Meshing and Element Type}

A good mesh form, shape, and size can provide accurate results with minimal computational time, so choosing the proper FE mesh is an essential factor. In this study, all sections were individually meshed with a global size of about $30 \mathrm{~mm}$. The 3D solid element, which includes concrete and steel plate were given the hexahedral 
element shape, while the 2D shell element, which includes CFRPs materials were given the quad-dominated element shape. Three element types were used to model the solid, wire, and shell components, depending on the model geometry. Figure 6 shows mesh used in the FE models.

\section{Interactions}

A constraint of type tie was used to define the interaction between concrete and CFRP materials, and concrete and steel plates. Accordingly, there is no relative motion between them. On the other hand, constraint of type embedded region was used to define the interaction between the concrete and the steel reinforcement, assuming perfectly bond between them with no slip.

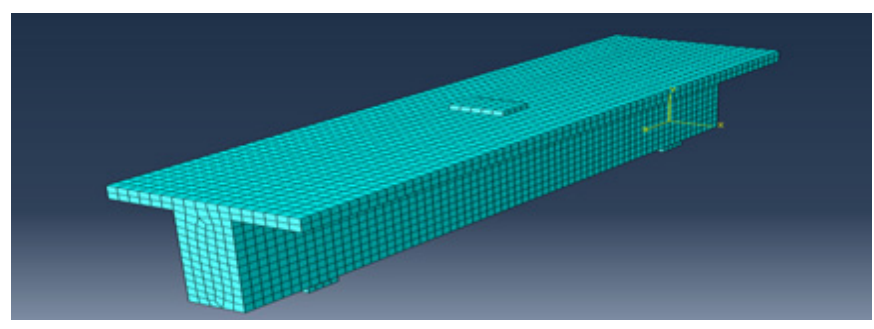

Figure 6: FE models meshing

\section{Boundary Conditions}

To simulate the pin and roller supports; the boundary conditions were added to the nodes line at the center of two steel plates under the beam, one of which allows the beam to rotate but not translate in either direction, and the other of which allows the beam to rotate and translate only in the z-direction.

\section{RESULTS and DISCUSSIONS}

\section{Experimental Ultimate Load}

All beams failed in shear. The experimental ultimate load and experimental load-deflection curves are shown in Table 3 and Figure 7 , respectively.

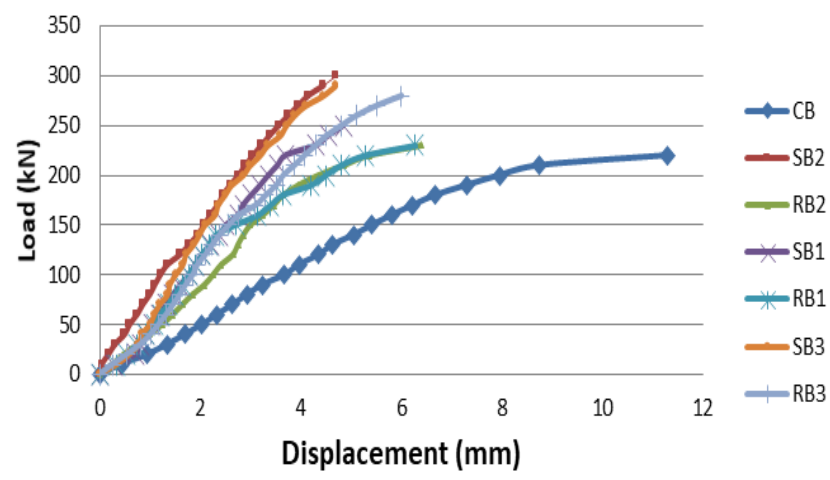

Figure 7: Experimental load-deflection curves for all beams

All the experimental results showed that using external CFRPs materials with different arrangements increased the ultimate load-carrying capacity by $13.6 \%, 36.4 \%$, and $31.8 \%$ for beams SB1, SB2 and SB3 of the group three (strengthened) respectively, and by $4.6 \%, 9.1 \%$ and $27.3 \%$ for beams RB1, RB2 and RB3 of the group four (rehabilitated), respectively, compared to the result of the CB1 beam. In group three (strengthened); the horizontal CFRP laminates showed the highest increase in the experimental shear capacity. While for group four (rehabilitated); the one layer sheet fully wrapped over entire web showed the highest increase in the experimental shear strength. On the other hand, the improvements of experimental shear strength were higher in group three (strengthened) compared to group four (rehabilitated). Table 4 shows the differences in the enhancement ratio between group three (strengthened) and group four (rehabilitated). This indicates that by pre-loading the samples up to $60 \%$ of their carrying capacity; part of their

Table 3: Experimental ultimate loads

\begin{tabular}{|c|c|c|c|}
\hline $\begin{array}{c}\text { Specimen } \\
\text { Name }\end{array}$ & $\begin{array}{c}\text { Experimental Ultimate Load } \\
(\mathrm{kN})\end{array}$ & $\begin{array}{c}\text { Experimental Maximum Mid-span } \\
\text { deflection } \\
(\mathrm{mm})\end{array}$ & $\begin{array}{c}\text { Ultimate load enhancement } \\
\text { ratio } \\
(\%)\end{array}$ \\
\hline CB1 & 220 & 11.3 & -- \\
\hline PB1 & 120 & 2 & -- \\
\hline PB2 & 100 & 1.2 & -- \\
\hline SB1 & 250 & 4.85 & 36.6 \\
\hline SB2 & 300 & 4.71 & 31.8 \\
\hline SB3 & 290 & 4.70 & 4.6 \\
\hline RB1 & 230 & 6.28 & 9.1 \\
\hline RB2 & 240 & 6.5 & 27.3 \\
\hline RB3 & 280 & 6 & \\
\hline
\end{tabular}


Table 4: Comparison between experimental results of strengthened and rehabilitated group

\begin{tabular}{|c|c|c|c|}
\hline & $\begin{array}{c}\text { Experimental Ultimate Load } \\
(\mathrm{kN}) \text { for Strengthened Group }\end{array}$ & $\begin{array}{c}\text { Experimental Ultimate Load } \\
(\mathrm{kN}) \text { for Rehabilitated Group }\end{array}$ & $\begin{array}{c}\text { Difference in the } \\
\text { enhancement ratio } \\
(\%)\end{array}$ \\
\hline Laminate (Inclined-45) & 250 & 230 & 9.0 \\
\hline Laminate (Horizontal) & 300 & 240 & 27.3 \\
\hline Sheet (Full Wrap) & 290 & 280 & 4.5 \\
\hline
\end{tabular}

capacity has been lost and has not been recovered when the load is removed. It can be concluded here that using CFRP materials is more efficient in strengthening than in rehabilitating. Regarding beams PB1 and PB2; the experimental ultimate loads were 120 and 100 kN, respectively as shown in Table 3. These results showed a good agreement with the theoretical calculation of Vctheo that was determined by the equations of $\mathrm{ACl} 318 \mathrm{M}-14$ [23] which was $119 \mathrm{kN}$.

\section{Crack patterns and modes of failure}

The crack patterns for all tested beams are shown in Figure 8. The modes of failure and crack patterns are discussed in this section for all the groups.

\section{Group One (CB)}

The failure mode of the $\mathrm{CB}$ was pure shear failure as shown in Figure 8(a). The first initial diagonal shear crack was observed at both shear spans at a load level of 90 $\mathrm{kN}$. As the load is further increased, flexural crack starts to appear at a load level of $160 \mathrm{kN}$. The diagonal cracks continued in appearing and the old ones extended until crushing occurred.

\section{Group Two (PB1 and PB2)}

Both beams failed in shear rather than flexure and the failure was brittle because those beams were plain concrete. Beam PB1 had the first shear and flexural crack at a load level of $85 \mathrm{kN}$. As the load is further increased, the cracks extended, widened, and propagated in length toward the top of the web until crushing occurred. For beam PB2, the first shear crack was observed at a load level of $70 \mathrm{kN}$ and the flexural crack at load level $55 \mathrm{kN}$. At the end the beam PB2 failed in shear at a load level of $100 \mathrm{kN}$. Figure 8(b) shows the crack patterns for PB1 beam.

\section{Group Three-Strengthened (SB1, SB2, and SB3)}

For SB1 beam; the first shear crack was observed at a load level of $140 \mathrm{kN}$. At the final stage of loading, the only diagonal crack that had appeared started to get wider. None of the CFRP laminates were completely separated from the concrete surface. Only partial separation of the laminates was observed. Figure 8(c) shows the crack patterns for SB1 beam. For SB2 beam and based on the CFRP laminates configuration; it was very difficult to mark and record the cracks on the side faces of the beam during the test due to the presence of the bonded CFRPs laminates. Nevertheless, the first formation of a diagonal shear crack was observed at a load level of $140 \mathrm{kN}$. With further increase in the load, the main diagonal crack developed further and additional shear cracks appeared. At a load level of $210 \mathrm{kN}$, separation of one end of the CFRPs laminates was noted at the right shear span, as shown in Figure 8(d) which gives rise to such type of de-bonding. Thereafter, the load was incrementally increased and the beam failure occurred at a load level of $300 \mathrm{kN}$. The failure mode of this beam was shear failure accompanied with separation of one of the CFRPs laminates. For SB3 beam; it was not possible to observe the formation of any cracks due to the continuous wrap of CFRPs sheets. Nevertheless, the applied load was incrementally increased by $10 \mathrm{kN}$ increments until it reached to $130 \mathrm{kN}$ where the CFRPs sheet started to rupture on the right side of the web. Thereafter, the load was incrementally increased and the beam failure occurred at a load level of $290 \mathrm{kN}$. The mode of failure was shear failure. Figure 8(e) shows the crack patterns for SB3 beam.

\section{Group Four-Rehabilitated (RB1, RB2, and RB3)}

For RB1; the failure mode was pure shear failure with partial de-bonding in some of strips edges as shown in Figure 8(f). It was noticed that the shear crack that appeared in the first stage of loading at $60 \%$ was the same crack that caused failure. With further increase in the load, the main diagonal crack developed further and additional shear cracks appeared until failure. For RB2; the failure mode of this beam was pure shear failure without any de-bonding as shown in Figure 8(g). Likewise the RB1 beam, the shear failure occurred on the same initial cracks in the pre-loading stage. However, additional shear cracks started to appear at a load level of 120 $\mathrm{kN}$. With further increase in the load, the main diagonal crack was getting wider until failure. For RB3; the failure mode of this beam was pure shear failure as shown in Figure $8(\mathrm{~h})$. The first shear crack started at the right side of the beam web. As was mentioned earlier, it was difficult to observe the cracks because of the continuity of the U-wrap. The beam reached a load level of $280 \mathrm{kN}$ and a mid-span deflection of $6 \mathrm{~mm}$ then it started to fail with pure shear cracks. 


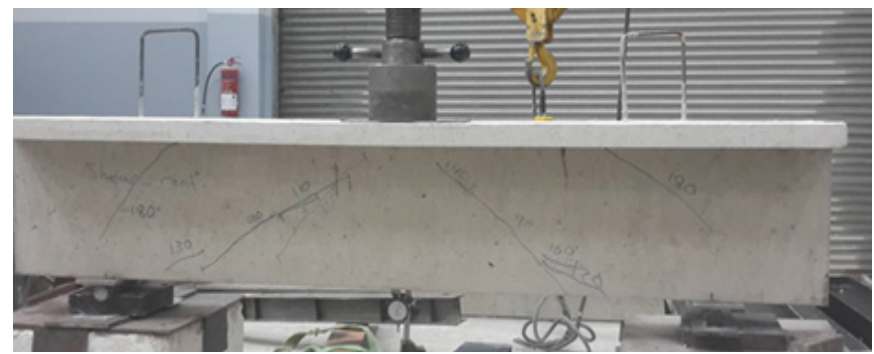

(a)

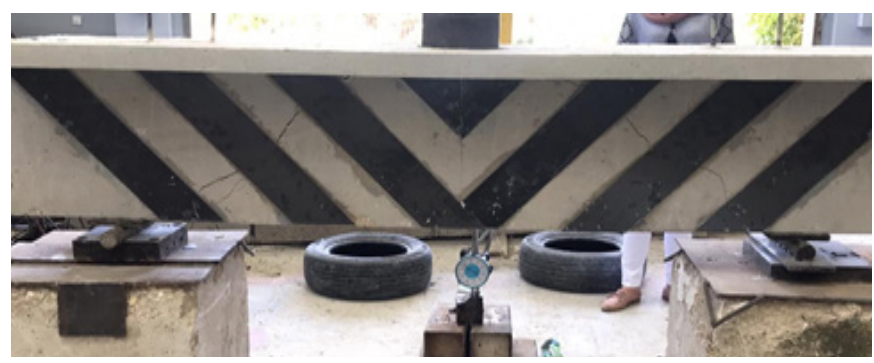

(c)

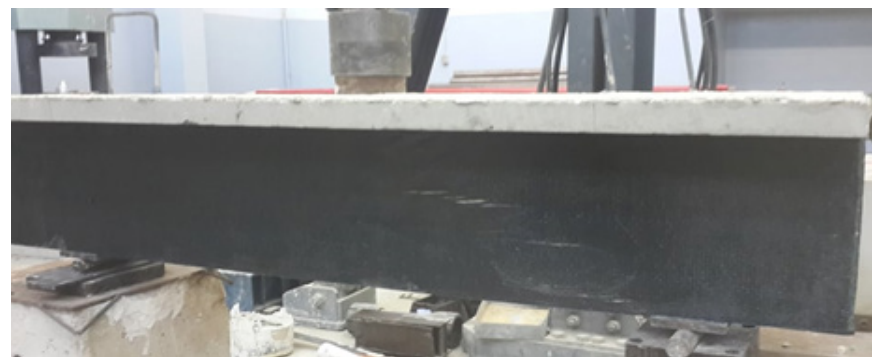

(e)

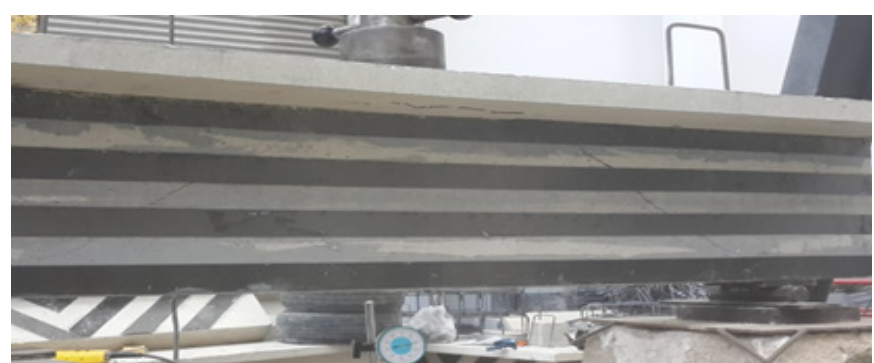

(g)

Figure 8: Crack patterns for beams: (a) $C B$; (b) PB1;

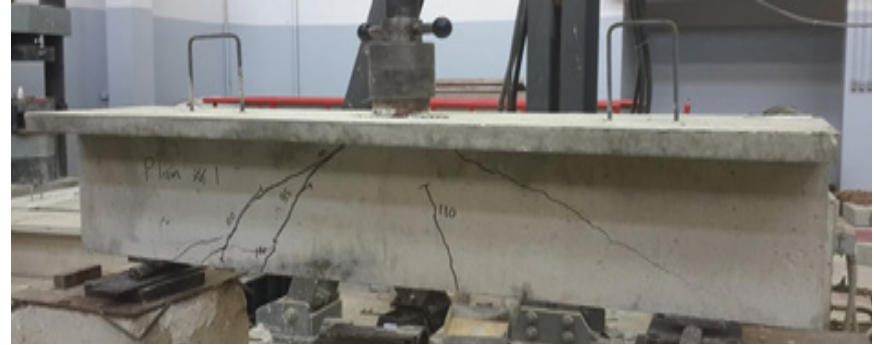

(b)

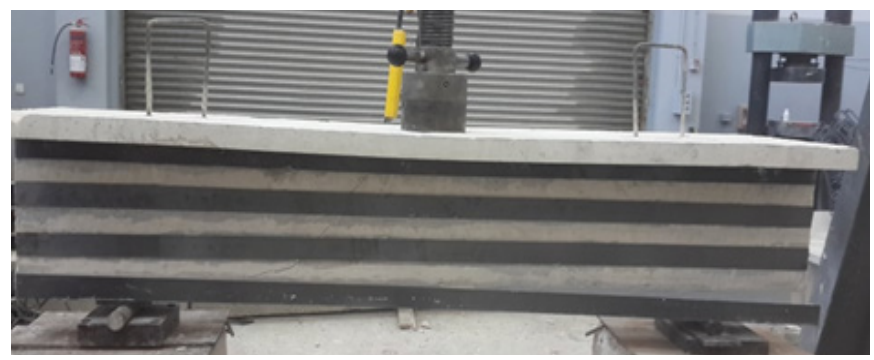

(d)

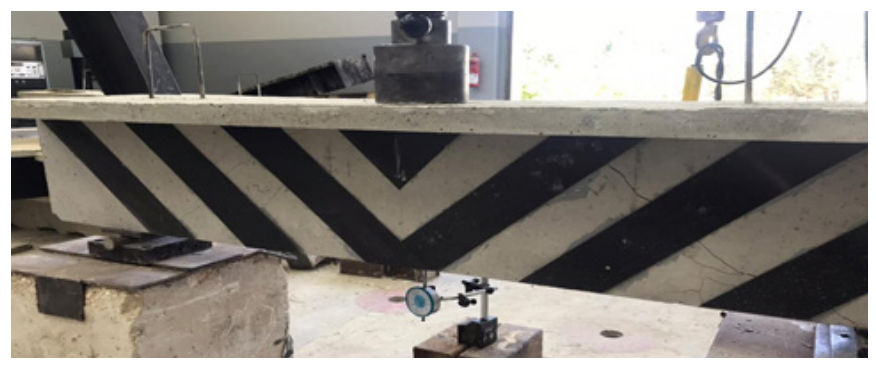

(f)

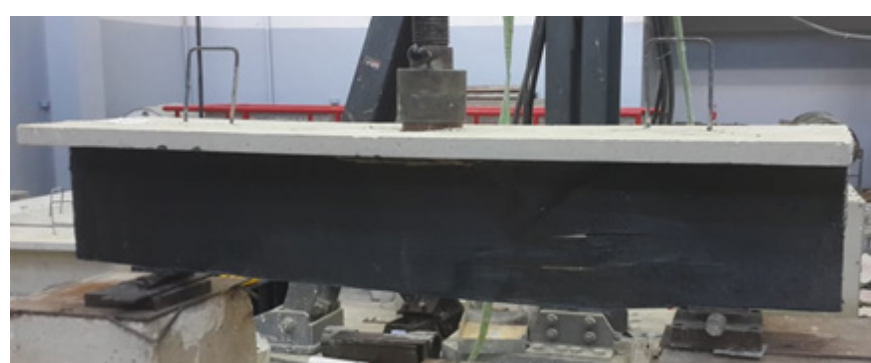

(h)

(c) SB1; (d) SB2; (e) SB3; (f) RB1; (g) RB2; (h) RB3

until $60 \%$ of the ultimate load of $\mathrm{CB}$; they did not return to their first state after removing the load. There was a permanent deformation of up to $2 \mathrm{~mm}$ according to FEA results. So when they were tested after being rehabilitated, at zero loads the deflection at mid-span was not zero in the FE models as was the case in the experimental curves. The cracks pattern of all beam using FE modeling are shown in Figure 10. The experimental and theoretical cracks pattern showed an excellent match. 
CB1

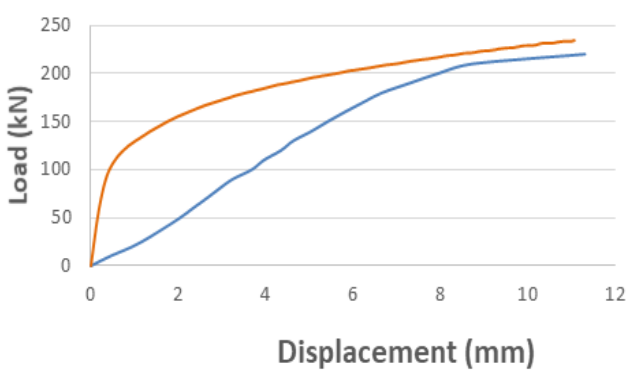

(a)

SB2

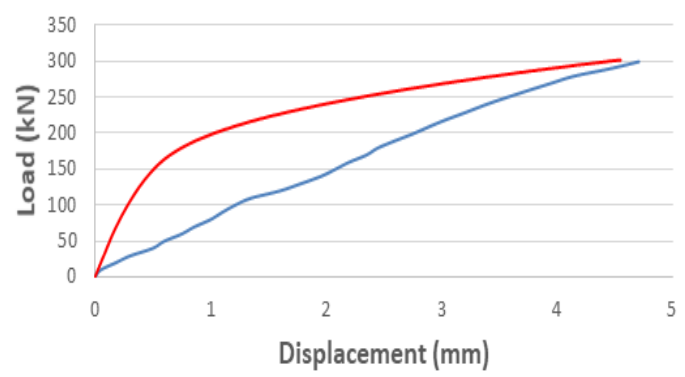

(c)

RB1

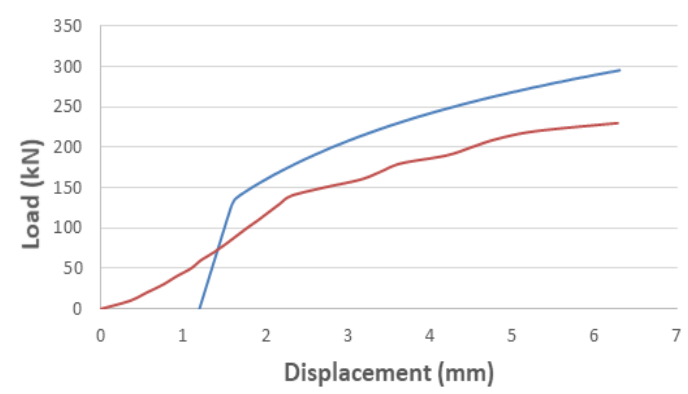

(e)

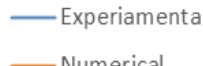

- Numerical

—Experimental

— Numerical

- Numerical
-Experimental

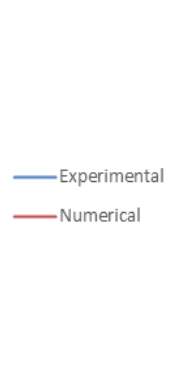

-

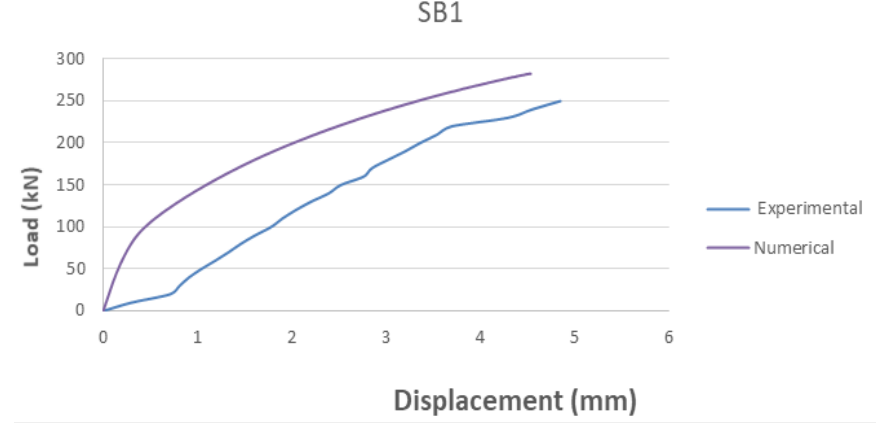

(b)

SB3

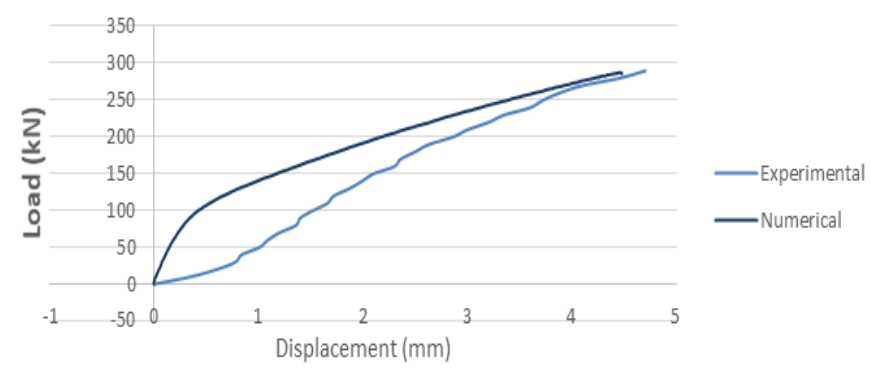

(d)

RB2

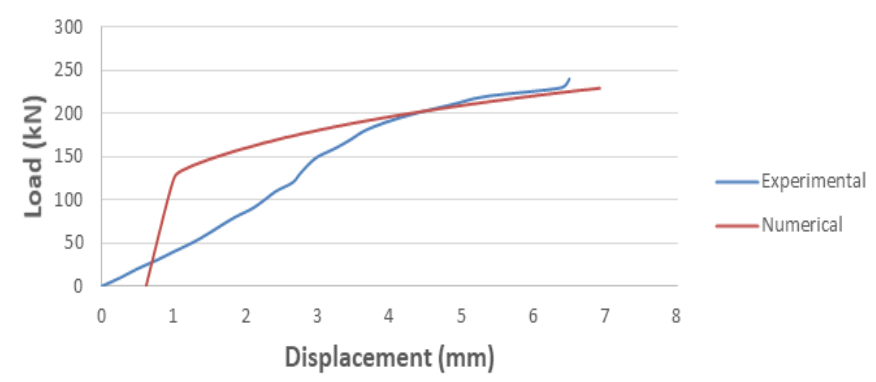

(f)

RB3

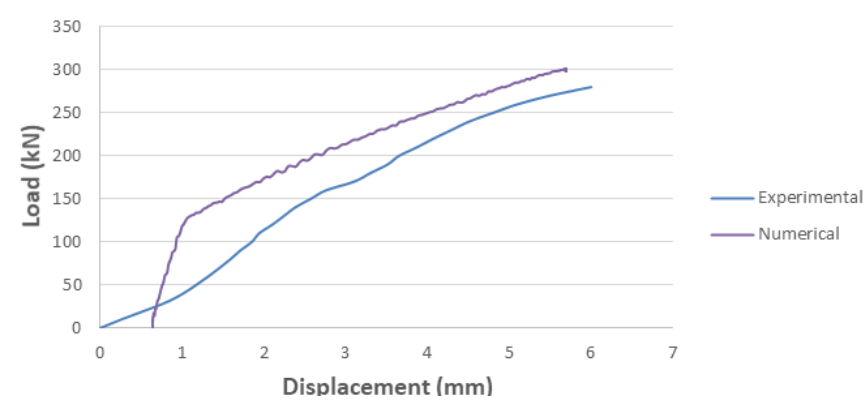

(g)

Figure 9: Comparison of load-deflection curves between experimental and FE for : (a) CB; (b) SB1; (c) SB2; (d) SB3; (e) RB1; (f) RB2; (g) RB3 


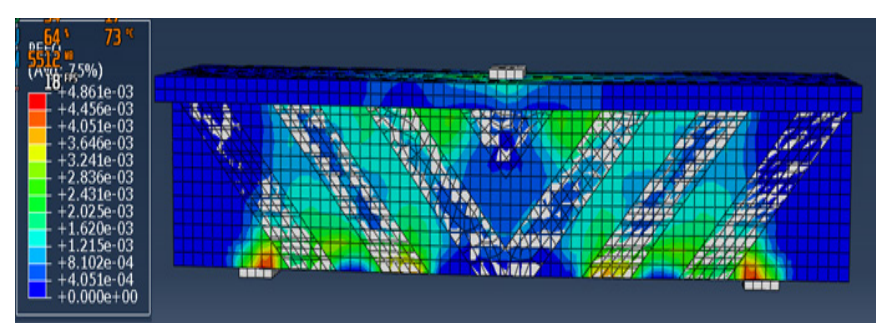

(a)

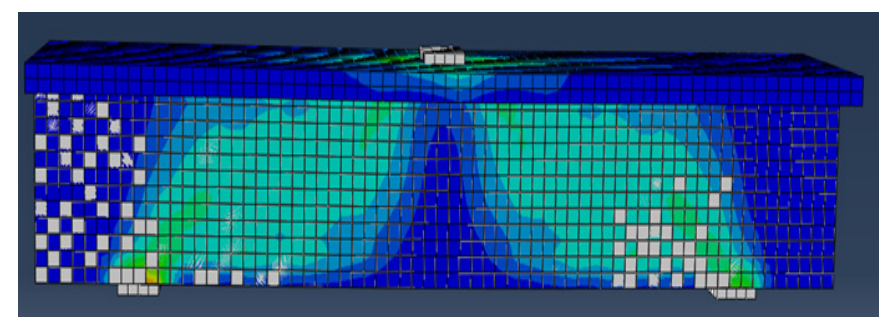

(c)

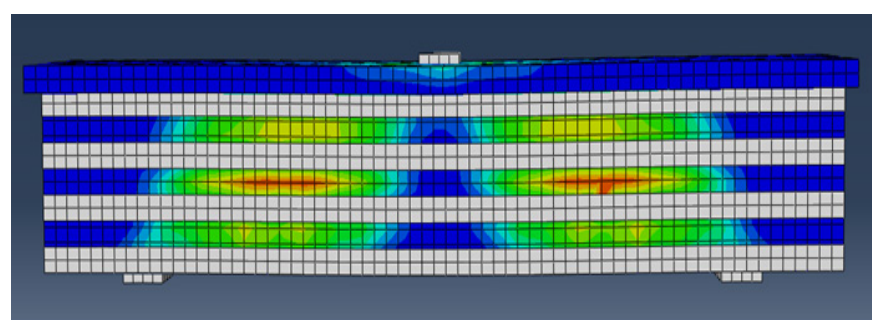

(e)

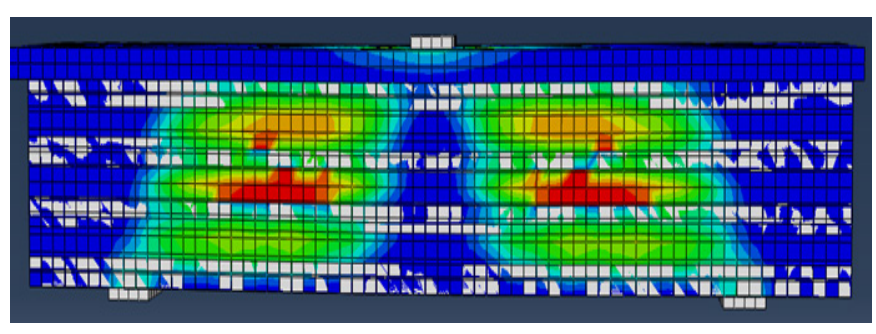

(b)

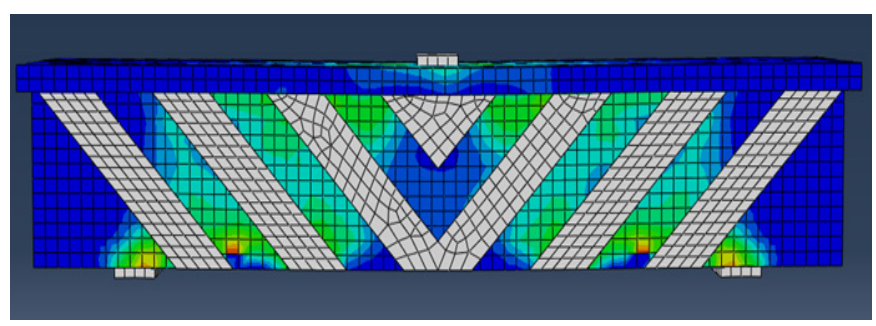

(d)

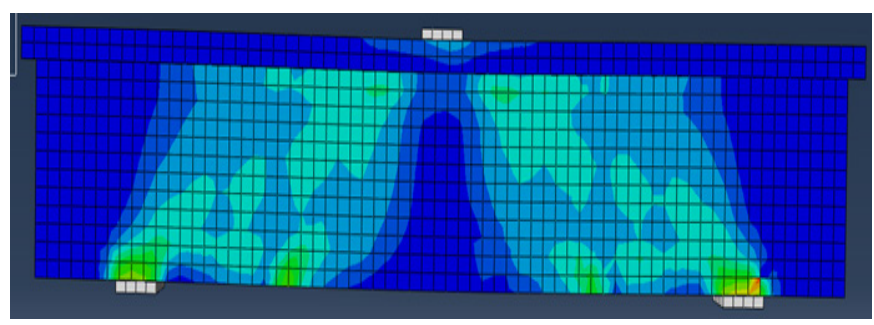

(f)

Figure 10: Crack patterns using FE models for : (a) SB1; (b) SB2; (c) SB3; (d) RB1; (e) RB2; (f) RB3

Table 5: Comparison between Experimental and FE results

\begin{tabular}{|c|c|c|c|c|c|c|}
\hline $\begin{array}{c}\text { Beam } \\
\text { designation }\end{array}$ & $\begin{array}{c}\text { Experimental } \\
\text { Load } \\
{[\mathrm{kN}]}\end{array}$ & $\begin{array}{c}\text { Load } \\
{[\mathrm{kN}]}\end{array}$ & $\begin{array}{c}\text { Difference in } \\
\text { Load }\end{array}$ & $\begin{array}{c}\text { Experimental } \\
\text { Deflection [mm] }\end{array}$ & $\begin{array}{c}\text { FE Deflection } \\
{[\mathrm{mm}]}\end{array}$ & $\begin{array}{c}\text { Difference in } \\
\text { Deflection }\end{array}$ \\
\hline CB1 & 220 & 234 & $6.36 \%$ & 11.30 & 11.07 & $2.04 \%$ \\
\hline SB1 & 250 & 280 & $12 \%$ & 4.85 & 4.53 & $6.60 \%$ \\
\hline SB2 & 300 & 301 & $0.33 \%$ & 4.71 & 4.55 & $3.40 \%$ \\
\hline SB3 & 290 & 286 & $1.38 \%$ & 4.70 & 4.47 & $4.89 \%$ \\
\hline RB1 & 230 & 290 & $26 \%$ & 6.28 & 6.3 & $0.32 \%$ \\
\hline RB2 & 240 & 229 & $4.58 \%$ & 6.5 & 6.9 & $6.15 \%$ \\
\hline RB3 & 280 & 289 & $3.21 \%$ & 6 & 5.7 & $5 \%$ \\
\hline
\end{tabular}

\section{CONCLUSION}

This paper studied experimentally and theoretically the improvement of shear capacity of strengthened and rehabilitated RC T-beams using different CFRPs materials and configurations. Based on the results, the following conclusions were drawn:

- Using externally bonded CFRPs in T-beams improved the shear capacity.

- Using externally bonded CFRPs in T-beams delayed the shear cracks, reduced the crack's propagation, and gave an overall stiffness enhancement.
- The two types of CFRPs materials, laminates and sheets, increased the ultimate load at different percentages depending on CFRPs scheme compared with the control beams.

- For the strengthening group the three schemes increased the maximum load capacity within a range of $13.6 \%$ to $36.4 \%$. The best configuration was using horizontal strips of laminates on the web.

- For the rehabilitation group the three schemes increased the maximum load capacity within a range of $4.6 \%$ to $27.3 \%$. The best configuration was using sheet wrapping the entire web of the beam. 
- The improvements in shear strength were higher in the strengthened group when compared to the rehabilitation group.

- A good agreement was found between the results of the experimental and theoretical results using FE ABAQUS software.

\section{ACKNOWLEDGEMENTS}

The authors would like to thank the dean of scientific research in the University of Jordan for partially funding the research.

\section{REFRENCES}

1. Nanni, A., (1995). Concrete Repair with Externally Bonded FRP Reinforcement. Concrete International, vol. 17, no.6, 22-26.

2. Wang, Y. C., Chen, C. H. (2003). Analytical study on reinforced concrete beams strengthened for flexure and shear with composite plates. Composite structures, vol. 59, no. 1, 137-148. DOI: 10.1016/S02638223(02)00171-X

3. Salib, M.N. (2012). Flexural Behavior of RC T- Section Beams Strengthened with Different Configurations of CFRP Laminates. International Journal of Current Engineering and Technology, vol. 2, no.4, 418-426.

4. Tanarslan H. M., Altin S. (2009). Behavior of RC T-section beams strengthened with CFRP strips, subjected to cyclic load. Materials and Structures, vol. 43, no. 4, 529-542. DOI: 10.1617/s11527-0099509-8.

5. Chajes M. J., Januszka T. F., Mertz D. R., Thomson T. A., Finch W. W. (1995). Shear strengthening of Reinforced Concrete beams using externally applied composite fabrics. ACI Structural Journal, vol. 92, no. 3, 295-303.

6. Khalifa A., Nanni A. (2000). Improving shear capacity of existing RC T-section beams using CFRP composites. Cement \& Concrete Composites, vol. 22, no. 3, 165-174. DOI: 10.1016/S0958-9465(99)00051-7

7. Jayaprakash J., Abdul Samad A.A, Ashrabov A.A, Choong K.K. (2009). Experimental Investigation on Shear Resistance Behaviour of RC Precracked and Non Precracked T-Beams using Discrete CFRP Strips. International Journal of Integrated Engineering, vol. 1, no. 2, 1-15.

8. Al-Hassani, H. M., Al-Ta'an, S. A. A. (2013). Behavior of damaged reinforced concrete beams strengthened with externally bonded steel plate. Tikrit Journal of Engineering Sciences, vol. 20, no. 2, 48-59.

9. Al-Ghanem, H., Al-Asi, A., Abdel-Jaber, M. S., Alqam, M. (2017). Shear and flexural behavior of reinforced concrete deep beams strengthened with CFRP composites. Modern Applied Science, vol. 11, no. $10,110-122$. DOI: 10.5539/mas.v11n10p110
10. Abdel-Jaber, M. S., Shatanawi, A. S., Abdel-Jaber, M. (2007). Guidelines for Shear Strengthening of Beams Using Carbon Fibre-Reinforced Polymer (FRP) Plates. Jordan Journal of Civil Engineering, vol. 1, no. 4, 327-335.

11. Yu F. ,Guo S,, Wang S., Fang Y. (2019). Experimental study on high pre-cracked RC beams shear-strengthened with CFRP strips. Composite Structures, vol. 225, no. 6, 111163. DOI: 10.1016/j. compstruct.2019.111163

12. Abed, D.J., Abdel- Jaber, M.S., Shatarat, N. (2018). Behavior of Square Reinforced-Concrete Columns Strengthened with Carbon Fiber Reinforced Polymers (CFRP) Under Eccentric Loading. International Journal of Civil Engineering and Technology, vol. 9, no. $11,532-547$.

13. Abdel-Jaber, M.S., Walker, P.R., Hutchinson, A.R. (2003). Shear Strengthening of Reinforced Concrete Beams Using Different Configurations of Externally Bonded Carbon Fibre Reinforced Plates. Materials and Structures Journal, vol. 36, 291-301.

14. Abdel-Jaber, M., (2001). Shear strengthening of reinforced concrete beams using externally bonded carbon fibre reinforced plates. PhD thesis, Oxford Brookes University.

15. Hassan, S. K., Abdel-Jaber, M. S., Alqam, M. (2018). Rehabilitation of Reinforced Concrete Deep Beams Using Carbon Fiber Reinforced Polymers (CFRP). Modern Applied Science, vol. 12, no. 8, 179-194. DOI:10.5539/mas.v12n8p179

16. [Bae W. , Belarbi A., Brancaccio A. (2011). Shear strengthening of full-scale RC T-Beams using externally bonded CFRP sheets. First Middle East Conference on Smart Monitoring, Assessment and Rehabilitation of Civil Structures.

17. Kim Y., Quinn K., Ghannoum W., Jirsa J. (2012). Strengthening of Reinforced Concrete T-Beams Using Anchored CFRP Materials. ACI Structuraljournal, vol. 111, no, 5, 1027-1036.

18. Soliman J. (2018). General behavior of T- section $\mathrm{RC}$ beams strengthened with epoxy-bonded carbon strands. MOJ Civil Engineering, vol. 4, no. 4, 213217.

19. El-Saikaly G., Godat A., Chaall O. (2015). New Anchorage Technique for FRP Shear-Strengthened RC T-Beams Using CFRP Rope. Journal of Composites for Construction, vol.19, no. 4. DOI: 10.1061/(ASCE) CC. $1943-5614.0000530$

20. Al Rjoub Y.S., Ashteyat, A.M., Obaidat, Y.T. Bani-Youniss, S. (2019). Shear strengthening of RC beams using near-surface mounted carbon fibre-reinforced polymers. Australian Journal of Structural Engineering, vol. 20, no. 1, 1-9. DOI:10.1080/1328 7982.2019.1565617 
21. Obaidat, Y.T., Barham, W.S., and Aljarah. A.H. (2020). New anchorage technique for NSM-CFRP flexural strengthened RC beam using steel clamped end plate. Construction and Building Materials, vol. 263, no. 3, 120246. DOI: 10.1016/j.conbuildmat.2020.120246

22. Abdel-Jaber M., Abdel-Jaber M.S., Katkhuda H., Shatarat N., and El-Nimri R. (2021). Influence of Compressive Strength of Concrete on Shear Strengthening of Reinforced Concrete Beams with Near Surface Mounted Carbon Fiber-Reinforced Polymer. Buildings, vol. 11, no. 11, 563, DOI: 10.3390/buildings. 11110563

23. ACl Committee 318 (2014). Building Code Requirements for Structural Concrete (ACl 318M-14) and Commentary. American Concrete Institute, Michigan: Farmington Hills.
24. Tsai, W. T. (1988). Uniaxial compressional stressstrain relation of concrete. Journal of Structural Engineering, vol. 114, no.9, 2133-2136. DOI: 10.1061/ (ASCE)0733-9445(1988)114:9(2133)

25. Yu T. ,Teng J.G., Wong Y.L., Dong S.L. (2010). Finite element modeling of confined concrete-II: Plastic-damage model. Engineering structures, vol. 32, no. 3, 680-691. DOI: 10.1016/j.engstruct.2009.11.013

26. ACl Committee 440 (2017), Guide for the Design and Construction of Externally Bonded FRP Systems for Strengthening Concrete Structures $(\mathrm{ACl}$ 440.2R-17). American Concrete Institute, Michigan: Farmington Hills.

27. ACl. 2009. Field Guide to Concrete Repair Application Procedures: Structural Crack Repair by Epoxy Injection (ACI RAP-1). Farmington Hills, MI: ACl. 